American Journal of Pharmacology and Toxicology 5 (2): 103-108, 2010

ISSN 1557-4962

(C) 2010 Science Publications

\title{
Cardioprotective Effect of Lagenaria siceraria (Molina) Standley (Cucurbitaceae) Fruit Juice on Doxorubicin Induced Cardiotoxicity in Rats
}

\author{
${ }^{1}$ M. Hassanpour Fard, ${ }^{2}$ G. Naseh, ${ }^{3}$ S.L. Bodhankar and ${ }^{4}$ M. Dikshit \\ ${ }^{1}$ Department of Pharmacology, \\ ${ }^{2}$ Department of Surgery, Imam Reza Hospital, \\ School of Medicine, Birjand University of Medical Sciences, Birjand, Iran \\ ${ }^{3}$ Department of Pharmacology, Poona College of Pharmacy, \\ Bharati Vidyapeeth University, Pune, India \\ ${ }^{4}$ Biochemistry Division, Department of Chemistry, \\ University of Pune, Pune, India
}

\begin{abstract}
Problem statement: The cardio toxicity of Doxorubicin (Dox) has limited its use as an anticancer drug. The aim of present study was to investigate the cardio protective effect of Lagenaria Siceraria (Cucurbitaceous) Fruit Juice (LSFJ) against the cardio toxicity of Dox in rats. Approach: Male wistar rats (250-300 g) were randomly divided into four groups. Group I- was control, Group II- Dox (10 mg kg-1), groups III and IV- Dox + LSFJ (5 and $10 \mathrm{~mL} \mathrm{~kg}^{-1}$ for 18 days). Dox $\left(10 \mathrm{mg} \mathrm{kg}^{-1}\right.$ iv) was administered in group II, III and IV on day 16 . After anesthetizing the animals on the 18th day, Electrocardiogram (ECG) was recorded and blood was investigated for Creatine Kinase-MB is enzyme (CK-MB), Lactate Dehydrogenase (LDH) and Aspartate Aminotransferase (AST) while determination of Superoxide Dismutase (SOD), Reduced Glutathione (GSH), Lipid Per Oxidation (LPO) and histopathology was carried out for heart. Results: Group 3 and 4 of animals showed decreased QT interval $(\mathrm{p}<0.05)$ and was non significant in ST interval and heart rate compared to Group 2. Significant decrease in serum CK-MB and AST of group $3(p<0.05)$ and group 4(p<0.01) of animals was observed as compared to group II. In group 4 significant increase in the level of GSH $(p<0.01)$ and decrease in MDA content $(\mathrm{p}<0.001)$ was observed as compared to group 2, whereas SOD was non-significant. Histopathological study of LSFJ10 mL kg-1 treated group showed protection against myocardial toxicity induced by doxorubicin. Conclusion: It is concluded that Lagenaria siceraria fruit juice possessed cardio protective effect at dose of $10 \mathrm{~mL} \mathrm{~kg}^{-1}$ against doxorubicin induced cardio toxicity in rats.
\end{abstract}

Key words: Antioxidant, electrocardiogram, histopathology, tissue parameters

\section{INTRODUCTION}

Lagenaria siceraria (Molina) Standley (Cucurbitaceae) fruit (bottle gourd), a commonly used vegetable in India is described as cardiotonic (Deshpande et al., 2008). Doxorubicin, an anthracycline antibiotic, has a broad antitumor spectrumand has been used against a wide variety of hematopoietic malignancies and solid tumors (Ogura, 2001). Unfortunately, the cardio toxicity of Dox, resulting in a cardiomyopathy with irreversible congestive heart failure and high mortality, is one of the main factors that limit its use. The molecular mechanisms explaining the cardio toxicity of anthracyclines are complex, but it appears that the induction of an oxidative stress within myocardial tissue constitutes a common denominator (Vergely et al., 2007). It is hypothesized that antioxidants and iron-chelators may protect the heart against Dox toxicity. Dexrazoxane is an iron chelator and possesses potent antioxidant properties and has been reported to prevent Dox induced cardio toxicity. However, due to the high incidence of dexrazoxane-induced myelosuppression, its use has been limited to some advanced stages of malignant disorders (Seifert et al., 1994). On the other hand, many plants have been reported to possess antioxidant activity. There is paucity of reports on the cardio protective activity of Lagenaria siceraria in Dox-induced cardio toxicity.

Corresponding Author: M. Hassanpour Fard, Department of Pharmacology, School of Medicine,

Birjand University of Medical Sciences, Birjand, Iran Tel: +98 9157401008 Fax: +98 5614430076 
The objective of the present study was to investigate the protective effects of LS fruit juice against Dox-induced cardio toxicity in rats.

\section{MATERIALS AND METHODS}

Animals: Male Wistar albino rats (250-300 g) obtained from Lupin Research Park, Pune, were housed under standard housing conditions of $25^{\circ} \mathrm{C}$, relative humidity $60 \%$ and photo period of $12 \mathrm{~h}$ dark/12 h light. Pellet diet (Chakan Oil Mills, Pune, India) and water were provided ad libitum. The protocol was approved by the Institutional Animal Ethics Committee (IAEC) of Poona College of pharmacy, Bharati Vidyapeeth University, Pune, India.

Chemicals and sample: The fruit of LS was purchased locally and authenticated by Dr. A.M. Mujumdar of Agharkar Research Institute, Pune, India. Doxorubicin powder was gifted by Serum Institute of India Ltd., Pune. CK-MB kit was purchased from Randox Laboratories Ltd., Ardmore, Diamond Road, Crumlin, Co. Antrim, United Kingdom, BT29 4QY and LDH as well as AST from Ecoline, Merck Ltd, Worli, Mumbai.

All solvents/chemicals used were of analytical grade and chemicals required for sensitive biochemical assays such as 5, 5-Dithiobis (2-Nitro Benzoic acid) (DTNB) and Thiobarbituric Acid (TBA) were purchased from Sigma Chemical Co., USA.

Experimental procedure: The animals were randomly divided into four groups (Group 1-control, Group 2-Dox, Group 3-LSFJ5 $\mathrm{mL} \mathrm{kg}^{-1}$ and Group 4LSFJ $10 \mathrm{~mL} \mathrm{~kg}^{-1}$ ) containing eight rats in each group. The body weights were recorded daily. LSFJ was administered ( 5 and $10 \mathrm{~mL} \mathrm{~kg}^{-1}$ ) orally to rats of group 3 and 4 daily for 18 days whereas Group 1 and 2 received distilled water. The control group received a single parenteral dose of sterile water for injection $\left(1 \mathrm{~mL} \mathrm{~kg}^{-1}\right)$ through femoral vein on the 16th day, while the groups 2, 3 and 4 received Dox $\left(10 \mathrm{mg} \mathrm{kg}^{-1}\right)$ dissolved in sterile water and injected within $1 \mathrm{~h}$. After $48 \mathrm{~h}$ of the injection, the rats were anaesthetized by anesthetic ether and ECG was recorded using 8 channels Power Lab System (AD Instruments Pty. Ltd., Unit 13, 18-22 Lexington Drive, Bella Vista NSW 2153, Australia) and the changes in QT and ST intervals and heart rate were computed from the ECG. Blood was withdrawn from Retro Orbital Plexus (ROP) for measuring serum parameters. The animals were allowed to recover and finally euthanized on the 18th day. The hearts of animals were removed and weighed. Four hearts were randomly selected for histopathology. The heart tissues from remaining four animals were processed and homogenized in $10 \%$ chilled tris hydrochloride buffer (10 mM, pH 7.4) by tissue homogenizer (Remi Motors, Mumbai, India) and centrifuged at $7500 \mathrm{rpm}$ for $15 \mathrm{~min}$ at $4^{\circ} \mathrm{C}$ using Eppendorf 5810-R high speed cooling centrifuge. The clear supernatant was used for the estimation of SOD, GSH, MDA content and total protein.

Serum parameters: Serum levels of CK-MB, LDH and AST enzymes were measured by automated chemistry analyzer, Micro lab 300, Merck, using reagent kits.

Tissue parameters: Lipid peroxidation assay (MDA content): This assay method was described by Slater and Sawyer (1971). In this method freshly prepared $0.67 \% \mathrm{w} / \mathrm{v}$ thiobarbituric acid reagent was used and the absorbance was measured by UV/VIS spectrophotometer (JASCO-V-530, Japan) at $532 \mathrm{~nm}$. Calibration curve was prepared by using 1, 1, 3, 3tetraethoxypropane as a standard.

Estimation of GSH: The assay of GSH was carried out using DTNB reagent as per the method described by Moron et al. (1979). The color developed was read at $412 \mathrm{~nm}$ against reagent blank. Standard glutathione was in the range of $(10-50 \mu \mathrm{g})$ and the content of reduced glutathione was expressed as $\mu \mathrm{g}$ of $\mathrm{GSH} \mathrm{g}^{-1}$ of protein.

Estimation of SOD activity: The SOD activity was assayed by the change in the optical density $\min ^{-1}$ at $480 \mathrm{~nm}$ of the reaction initiated by epinephrine bitartarate $(3 \mathrm{mM})$ as described by Misra and Fridovich (1972). SOD activity was expressed as units $\mathrm{mg}^{-1}$ protein. Change in optical density per min at $50 \%$ inhibition of epinephrine to adrenochrome transition by the enzyme was taken as the enzyme unit. Calibration curve was prepared by using 10-125 units of SOD.

Determination of total protein: Protein concentrations were determined using the method of Lowry et al. (1951). Diluted membrane fraction aliquots were taken and color developed by adding of 1N Folin's phenol reagent was measured at $640 \mathrm{~nm}$ against reagent blank. Different concentrations $(40-200 \mu \mathrm{g})$ of standard protein Bovine Serum Albumin (BSA) were used for standard curve. The values were expressed as $\mathrm{mg}$ of protein $\mathrm{g}^{-1}$ of wet tissue $\left(\mathrm{mg} \mathrm{g}^{-1}\right)$. 
Histopathological studies: Heart preserved in $10 \%$ formalin, processed and embedded in paraffin. Four $\mu \mathrm{m}$ thick paraffin sections were cut on glass slides and stained with Hematoxylin and Eosin $(\mathrm{H}$ and $\mathrm{E})$ reagents and observed under light microscope to evaluate myocardium injury.

Heart weight to body weight ratio: In each group, heart weight to body weight ratio was calculated. Body weight was the weight of animal on the day of sacrifice. Heart weight was measured after placing the heart in cold saline and squeezing out the blood.

Statistical analysis: The data was expressed as mean \pm Standard Error of Mean (SEM). One way Analysis Of Variance (ANOVA) was applied to test the significance of difference between average biochemical and ECG parameters of different groups with correction for multiple comparisons by the Tukey's test. P-value less than 0.05 was considered statistically significant. The entire statistical analysis was performed using statistical package called Graph pad prism version 4.03 (Graph pad software, Inc. USA).

\section{RESULTS}

ECG changes: Doxorubicin administration significantly increased QT $(\mathrm{p}<0.01)$ and ST $(\mathrm{p}<0.05)$ intervals compared to control group. LSFJ $10 \mathrm{~mL} \mathrm{~kg}^{-1}$ administration significantly decreased QT interval $(\mathrm{p}<0.05)$ while heart rate and ST interval were non significant compared to Dox group (Table 1).

Serum parameters: Administration of Dox (10 $\mathrm{mg} \mathrm{kg}^{-1}$ ) increased serum CK-MB, LDH and AST levels compared to that of control, whereas LSFJ (5 and $10 \mathrm{~mL} \mathrm{~kg}^{-1}$ ) administration decreased the levels of CK-MB and AST significantly compared to that of Dox alone. The level of LDH decreased non significantly (Table 2).

Tissue parameters: There was a significant increase $(\mathrm{p}<0.01)$ in MDA contents in the Dox group compared to the control group. Significant decrease in the level of MDA contents was observed in group IV $(\mathrm{p}<0.001)$ in comparison to group II. Significant $(\mathrm{p}<0.001)$ decrease in myocardial GSH was observed in Dox group compared to control group. In group IV there was significant increase $(\mathrm{p}<0.01)$ of myocardial GSH compared to Dox group. In groups 3 and 4 increase in
SOD was not statistically significant compared to Dox group, whereas SOD in Dox group decreased significantly $(\mathrm{p}<0.05)$ compared to control group (Table 3).

Histopathological changes: The incidence of marked tissue injury with myocardial atrophy, nuclear pyknosis, cytoplasmic vacuoles and cytoplasmic eosinophilia were observed in doxorubicin treated group. Control group showed normal myocardial structure. Treatment of LS FJ $5 \mathrm{~mL} \mathrm{~kg}$-1 for 18 days showed week protection against doxorubicin induced myocardial damage, whereas LSFJ $10 \mathrm{~mL} \mathrm{~kg}^{-1}$ for 18 days showed moderate protection. There was no change in the incidence of inflammation and vascular congestion in the four study groups (Fig. 1).

Table 1: Effect of Dox $\left(10 \mathrm{mg} \mathrm{kg}^{-1}\right)$ and LSFJ (5 and $\left.10 \mathrm{~mL} \mathrm{~kg}^{-1}\right)+$ Dox on ECG changes

\begin{tabular}{llll}
\hline $\begin{array}{l}\text { Groups/ } \\
\text { treatment kg }\end{array}$ & $\begin{array}{l}\text { ST interval } \\
(\mathrm{m} \mathrm{sec})\end{array}$ & $\begin{array}{l}\text { QT interval } \\
(\mathrm{m} \mathrm{sec})\end{array}$ & $\begin{array}{l}\text { Heart rate } \\
(\mathrm{bpm})\end{array}$ \\
\hline Control & $36.00 \pm 1.95$ & $66.88 \pm 1.56$ & $353.8 \pm 16.17$ \\
Dox $10 \mathrm{mg}$ & $43.14 \pm 1.86^{*}$ & $76.86 \pm 1.99^{* *}$ & $308.3 \pm 12.47^{\mathrm{NS}}$ \\
LSFJ $5 \mathrm{~mL}+$ & $38.25 \pm 1.25^{\mathrm{NS}}$ & $69.38 \pm 1.56^{+}$ & $300.5 \pm 14.13^{\mathrm{NS}}$ \\
$\begin{array}{l}\text { Dox } 10 \mathrm{mg} \\
\text { LSFJ } 10 \mathrm{~mL}+\end{array}$ & $37.75 \pm 2.21^{\mathrm{NS}}$ & $67.50 \pm 1.85^{+}$ & $335.7 \pm 24.50^{\mathrm{NS}}$ \\
Dox $10 \mathrm{mg}$ & & &
\end{tabular}

Note: Values are mean \pm SEM; ${ }^{*}$ : p-value compares Dox with control group while ${ }^{+}$: p-value compares Dox with LSFJ + Dox groups. *: $\mathrm{p}<0.05,{ }^{* *}: \mathrm{p}<0.01,^{+}: \mathrm{p}<0.05$, NS: Non Significant

Table 2: Changes in the levels of CK-MB, LDH and AST enzymes in the four experimental groups

Groups/

treatment kg ${ }^{-1} \quad$ CK-MB $\left(\mathrm{IU} \mathrm{L}^{-1}\right) \quad \mathrm{LDH}\left(\mathrm{IU} \mathrm{L}^{-1}\right) \quad$ AST $\left(\mathrm{IU} \mathrm{L}^{-1}\right)$

\begin{tabular}{llll}
\hline Control & $82.8 \pm 15.71$ & $179.8 \pm 19.97$ & $201.2 \pm 24.59$
\end{tabular}

Dox $10 \mathrm{mg} \quad 220.8 \pm 18.83^{* * *} \quad 393.4 \pm 38.54^{* * *} \quad 377.4 \pm 15.53^{* * *}$

LSFJ $5 \mathrm{~mL}+$ Dox $\quad 153.0 \pm 4.74^{+} \quad 308.6 \pm 10.07^{\mathrm{NS}} \quad 297.8 \pm 20.2^{+}$

$10 \mathrm{mg}$

LSFJ $10 \mathrm{~mL}+$ Dox $\quad 126.0 \pm 20.01^{++} \quad 293.0 \pm 11.16^{\mathrm{NS}} \quad 270.3 \pm 11.91^{++}$

$10 \mathrm{mg}$

Note: Values are expressed as mean \pm SEM; ${ }^{*}: p$ value compares Dox with control group while ${ }^{+}$: p value compares Dox with LSFJ + Dox groups. ${ }^{* * *}: \mathrm{p}<0.001,{ }^{+}: \mathrm{p}<0.05,{ }^{++}: \mathrm{p}<0.01$, NS: Non Significant

Table 3: The levels of MDA, GSH and SOD in the heart tissue of four experimental groups in $\mathrm{mg}$ of protein

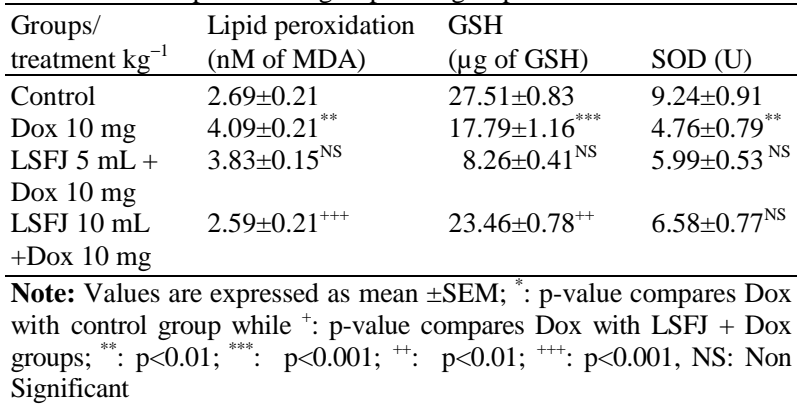
Significant 

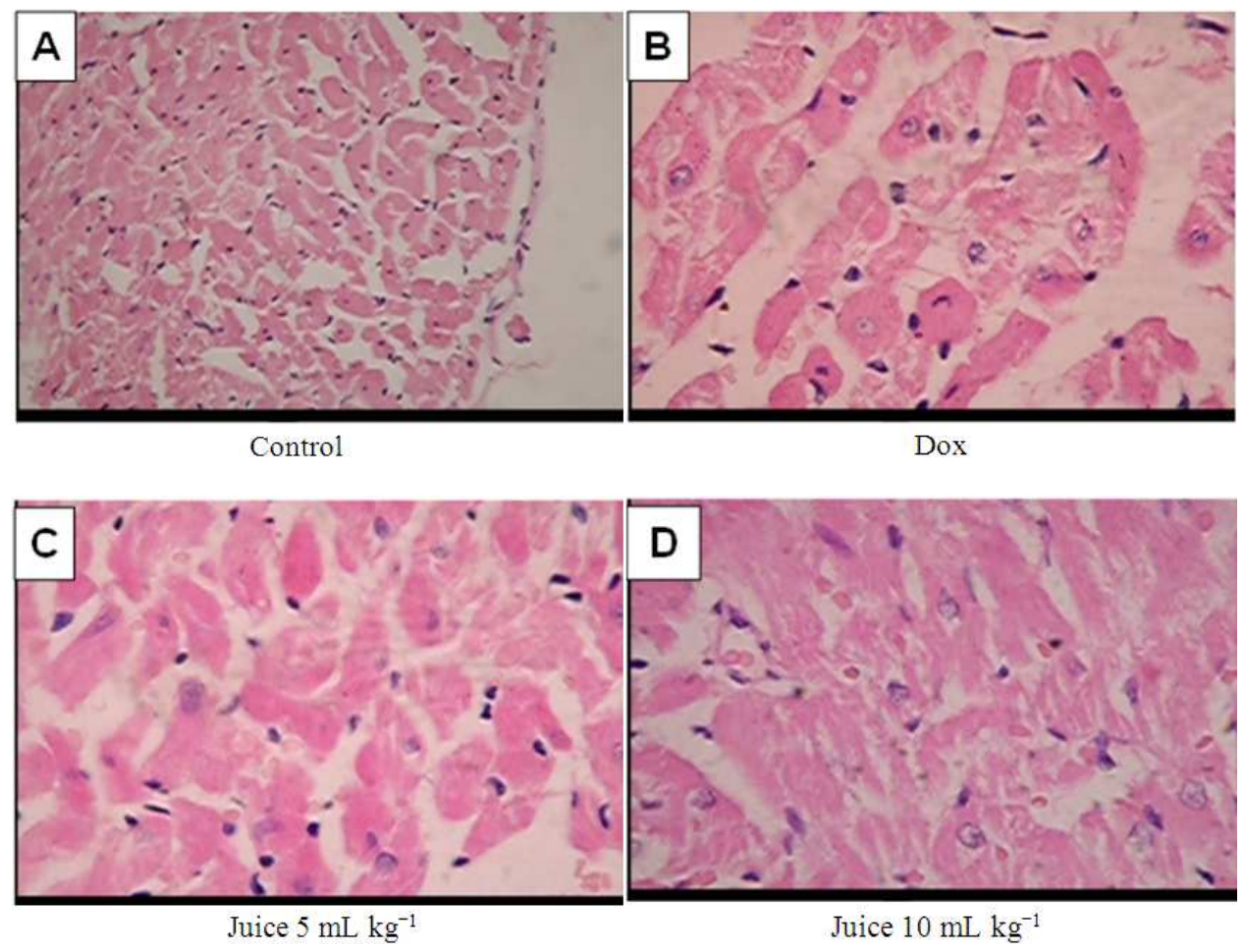

Fig. 1: Histopathological changes of rat heart (A) Control: Normal histological structure of rat heart; (B) Treated with Dox (10 mg kg-1 on day 16), showing sever nuclear pyknosis and cytoplasmic vacuoles in the rat heart; (C) Treated with LSFJ (5 mL kg${ }^{-1}$ for 18 day) + Dox showing moderate to sever type of nuclear pyknosis and cytoplasmic vacuoles than Dox treated animals. (D) Treated with LSFJ (10 mL kg-1 for 18 day) + Dox showing mild type of nuclear pyknosis and cytoplasmic vacuoles than Dox treated animals. (Magnification $40 \mathrm{X}$ and $100 \mathrm{X})$

\section{DISCUSSION}

Doxorubicin, which possesses potential for generating free radicals, causes an unusual and often irreversible cardiomyopathy. It has quinone and hydroquinone moieties that can form semiquinone radical intermediates, which in turn can react with oxygen to produce superoxide anion radicals. These can generate both hydrogen peroxide and hydroxyl radicals $(\cdot \mathrm{OH})$, which attack DNA and oxidize DNA bases (Serrano et al., 1999). The production of free radicals is significantly stimulated by the interaction of Dox with iron (Chabner et al., 2006). Doxorubicin treatment changes ECG and causes prolongation of QT interval in rats (Cirillo et al., 2000).

The results of present study clearly demonstrated that there was increase in myocardial injury as indicated by increase in QT and ST intervals of ECG pattern in Dox treated group. Administration of LSFJ along with Dox $\left(10 \mathrm{mg} \mathrm{kg}^{-1}\right)$ restored QT and ST intervals close to control level.
The results also demonstrated that acute administration of doxorubicin induced cardio toxicity manifested by a significant increase in serum CK-MB, AST and LDH. These results are consistent with previous studies (Mostafa et al., 1999; SayedAhmed et al., 2001; Saad et al., 2001). In the present study the serum levels of CK-MB and AST in LSFJ treated groups decreased significantly.

The most abundant Reactive Oxygen Species (ROS) generated in living cells are superoxide anion and its derivatives, particularly highly reactive and damaging hydroxyl radical, which induces per oxidation of cell membrane lipid (Hemnani and Parihar, 1998). In this respect, any increase in SOD activity of the organ appears to be beneficial in the event of increased free radical generation. A single dose administration of Dox $\left(10 \mathrm{mg} \mathrm{kg}^{-1}\right)$ caused a significant increase in MDA content (an index of lipid peroxidation) in cardiac tissues and decrease in myocardial GSH compared to control group indicating an increase in oxidative stress. 
Table 4: The average of heart weight to body weight ratio in four study groups

\begin{tabular}{ll}
\hline Groups/treatment/kg & Heart weight to body weight ratio \\
\hline Control & $2.72 \pm 0.02 \times 10^{-3}$ \\
Dox $10 \mathrm{mg}$ & $2.67 \pm 0.11 \times 10^{-3}$ \\
LSFJ $5 \mathrm{~mL}+$ Dox $10 \mathrm{mg}$ & $2.69 \pm 0.04 \times 10^{-3}$ \\
LSFJ $10 \mathrm{~mL}$ + Dox $10 \mathrm{mg}$ & $2.71 \pm 0.07 \times 10^{-3}$
\end{tabular}

Note: Values are expressed as mean \pm SEM. There was no statistical significant difference between the averages of ratio across the groups

These results correlate with previous studies which have demonstrated the involvement of oxidative stress and lipid peroxidation in doxorubicin induced cardiomyopathy (Fadillioglu et al., 2004; Patil and Balaraman, 2005). Administration of LSFJ improved the biochemical marker levels indicating decrease in oxidative stress as evident by increased level of GSH and SOD with decreased lipid peroxidation. LSFJ contains polyphenolic compounds $(6.8 \mathrm{mg} / 10 \mathrm{~mL}$ of juice, obtained by our group). The antioxidant activity of polyphenolic compounds from others plants have been reported earlier (Karou et al., 2005; Maisuthisakul et al., 2007).

Histopathological studies revealed myocardial atrophy, nuclear pyknosis, cytoplasmic vacuoles and cytoplasmic eosinophilia in Dox treated rat heart. Similar observations have also been made in earlier studies on acute doxorubicin induced cardiotoxicity (Saad et al., 2001; Morishima et al., 1998). Histopathological observations showed less damage in LSFJ $10 \mathrm{~mL} / \mathrm{kg}$ + Dox group than Dox group.

Doxorubicin also causes decrease in heart weight to body weight ratio, which indicates loss of myofibrils and cytoplasmic vacuolization in myocytes (Mukherjee et al., 2003). In this study the average of heart weight to body weight ratio in Dox group was not statistically significant compared to control group as well as LSFJ + Dox treated groups Table 4.

\section{CONCLUSION}

It is thus concluded that LSFJ administration prevented Dox-induced cardiotoxicity and decreased myocardial injury by preservation of endogenous antioxidants and reduction of lipid peroxidation in rat heart.

\section{ACKNOWLEDGEMENT}

The researchers acknowledge Dr. S.S. Kadam, vice chancellor, Dr. K.R. Mahadik, Principal, Poona College of Pharmacy for their keen interest in this study. We also thank Lupin research Park for donation of rats, Dr.
S. Joshi, A.E. Ghule and C. Kulkarni for their help in this study.

\section{REFERENCES}

Chabner, B.A., P.C. Amrein, B.J. Druker, M.D. Michaelson and C.S. Mitsiades et al., 2006. Antineoplastic Agents. In: Goodman and Gilman's the Pharmacological Basis of Therapeutics, Brunton, L.L., J.S. Lazo and K.L. Parker (Eds.), 11th Edn., McGraw-Hill Company, USA., ISBN: 0-07-142280-3, pp: 1315-1403.

Cirillo, R., G. Sacco, S. Venturella, J. Brightwell and A. Giachetti et al., 2000. Comparison of doxorubicin and MEN 10755-induced long-term progressive cardiotoxicity in the rat. J. Cardiovasc. Pharm., 35: 100-108.

Deshpande, J.R., A.A. Choudhari, M.R. Mishra, V.S. Meghre and S.G. Wadodkar et al., 2008. Beneficial effects of Lagenaria siceraria (Mol.) Standley fruit epicarp in animal models. Indian J. Exp. Biol., 46: 234-242. PMID: 18512332

Fadillioglu, E., E. Oztas, H. Erdogan, M. Yagmurca and S. Sogut et al., 2004. Protective effects of caffeic acid phenethyl ester on doxorubicin-induced cardiotoxicity in rats. J. Applied Toxicol., 24: 47-52. http://lib.bioinfo.pl/pmid:14745846

Hemnani, T. and M.S. Parihar, 1998. Reactive oxygen species and oxidative DNA damage. Indian $\mathrm{J}$. Physiol. Pharmacol., 42: 440-452. PMID: 10874342

Karou, D., M.H. Dicko, J. Simpore and A.S. Traore, 2005. Antioxidant and antibacterial activities of polyphenols from ethnomedicinal plants of Burkina Faso. Afr. J. Biotechnol., 4: 823-828. http://www.academicjournals.org/AJB/abstracts/ab s2005/Aug/Karou\%20et\%20al.htm

Lowry, O.H., N.J. Rosenbrough, A.C. Farr and R.J. Randell, 1951. Protein measurement with the folin-phenol reagent. J. Biol. Chem., 193: 265-275. http://www.jbc.org/cgi/reprint/193/1/265

Maisuthisakul, P., M. Suttajit and R. Pongsawatmanit, 2007. Assessment of phenolic content and free radical scavenging capacity of some Thai indigenous plants. Food Chem., 100: 1409-1418. DOI: 10.1016/J.FOODCHEM.2005.11.032

Misra, H.P. and I. Fridovich, 1972. The role of superoxide anion in the auto-oxidation of epinephrine and a simple assay for superoxide dismutase. J. Biol. Chem., 247: 3170-3175. PMID: 4623845 
Morishima, I., H. Matsui, H. Mukawa, K. Hayashi and Y.T. Toki et al., 1998. Melatonin, a pineal hormone with antioxidant property, protects against adriamycin cardiomyopathy in rats. Life Sci., 63: 511-521. DOI: 10.1016/S07351097(98)81113-3

Moron, M.S., J.W. Depierre and B. Mannervik, 1979. Levels of glutathione, glutathione reductase and glutathione S-transferase activities in rat lung and liver. Biochim. Biophys. Acta, 582: 67-78. PMID: 760819

Mostafa, A.M., M.N. Nagi, A.C. Al-Rikabi, O.A. Al-Shabanah and H.A. El-Kashef, 1999. Protective effect of aminoguanidine against cardiovascular toxicity of chronic doxorubicin treatment in rats. Res. Commun. Mol. Pathol. Pharmacol., 106: 193-202. PMID: 11485049

Mukherjee, S., S.K. Banerjee, M. Maulik, A.K. Dinda and K.K. Talwar et al., 2003. Protection against acute adriamycin-induced cardiotoxicity by garlic: Role of endogenous antioxidants and inhibition of TNF- $\alpha$ expression. BMC Pharmacol., 3: 16. PMID: 14687418

Ogura, M., 2001. Adriamycin (doxorubicin). Gan Kagaku Ryoho, 28: 1331-1338. PMID: 11681238

Patil, L. and R. Balaraman, 2005. Protective effect of green tea extract on doxorubicin induced cardiotoxicity in rats. OPEM, 5: 137-143. http://opem.org/board_pds/content_detail.asp?idx= $297 \&$ volume $=5$

Saad, S.Y., T.A. Najjar and A.C. Al-Rikabi, 2001. The preventive role of deferoxamine against acute doxorubicin- induced cardiac, renal and hepatic toxicity in rats. Pharmacol. Res., 43: 211-218. DOI: $10.1006 /$ phrs.2000.0769
Sayed-Ahmed, M.M., M.M. Khattab, M.Z. Gad and A.M. Osman, 2001. Increased plasma endothelin1 and cardiac nitric oxide during doxorubicininduced cardiomyopathy. Pharmacol. Toxicol., 89: 140-144.

http://www.ingentaconnect.com/content/mksg/pto/ 2001/00000089/00000003/art00005

Seifert, C.F., M.E. Nesser and D. Thompson, 1994. Dexrazoxane in the prevention of doxorubicininduced cardiotoxicity. Ann. Pharmacother., 28: $1063-1072$. PMID: 7803884 http://www.druglib.com/abstract/se/seifert-cf_annpharmacother_19940900.html

Serrano, J., C.M. Palmeira, D.W. Kuehl and K.B. Wallace, 1999. Cardioselective and cumulative oxidation of mitochondrial DNA following subchronic doxorubicin administration. Biochem. Biophys. Acta, 1411: 201-205. DOI: 10.1016/S0005-2728(99)00011-0

Slater, T.F. and B.C. Sawyer, 1971. The stimulatory effects of carbon tetrachloride and other halogenoalkanes or peroxidative reactions in rat liver fractions in vitro. Biochem. J., 123: 805-814. PMID: 4399399

Vergely, C., S. Delemasure, Y. Cottin and L. Rochette, 2007. Preventing the cardiotoxic effects of anthracyclines: From basic concepts to clinical data. Heart Metab., 35: 1-7. http://www.heartandmetabolism.org/pdf/35/8.pdf 